\title{
Designing and Developing a GIS Database for Tourism in Aurangabad: A Review
}

\author{
Monali Rajendra Baviskar \\ Department of Computer Science \& Information Technology, \\ Dr.Babasaheb Ambedkar Marathawada University. \\ Aurangabad, India
}

\begin{abstract}
Tourism has been noted to be one of the important and growing sectors of the Aurangabad economy. Tourism is a highly complex activity which requires tools that aid in an effective decision-making to come to terms with the better economic, social and environmental demands of sustainable development. Geographic Information System (GIS) is one of such tools for tourism. GIS being Associate in Nursing system that's capable of responsive questions about wherever facilities and resources are placed represents monumental edges to the commercial enterprise sector of any economy. The power of GIS lies not solely examine spatial relationships, however additionally on the far side the space to the holistic read of the globe with its several interconnected parts and complicated relationships. The use of GIS technology could assist the Maharashtra State government as well as the Aurangabad Corporation with better planning of tourism location, infrastructure and dissemination of such infrastructure as well as production of better quality maps showing tourists sites etc because of the dynamic capability of GIS tools to include changes that occur over time to its database. A GIS database for tourism in Aurangabad city will be created using tourist attractions and facilities, some selected roads with the help of base maps and GPS. This paper presents the significant role that GIS can play in tourism for development in Aurangabad when complete GIS database for tourism in the City is designed and developed.
\end{abstract}

\section{Keywords}

Geographic information systems (GIS), Aurangabad, GPS, KML.

\section{INTRODUCTION}

Tourism is one amongst the necessary major sources of financial gain within the world these days and a vital export business and chief of exchange in several countries like us of America (U.SA.), UK, Germany, China, and European country commercial enterprise is currently the greener pastures most developing countries have centered attention to because of its huge advantages like infrastructural development, job creation, conservation of atmosphere etc. In Aurangabad, it's a vital sector that's under development. Touristy has traditionally been dependent on the character of the destination, together with manmade attractions, Historic attractions and resorts. It's a trendy activity that needs the provision of sure parameters (e.g. accessible road networks, normal accommodation facilities, attractions etc) and knowledge on potential and existing attraction sites. data on these parameters and attraction sites will be gathered, processed, organized and hold on using tools like global Positioning System (GPS), Geographic information system (GIS) in addition to remote sensing. once gathering the required information a couple of destination, the information should be hold on in an exceedingly recoverable kind to boost touristry, and this will be achieved with the help of GIS.

Geographic information Systems (GIS) is one amongst the most outstanding technologic innovations in touristry designing and decision making. "Both GIS and tourism share a typical characteristic, that is, each cross the boundaries of disciplines and application areas. GIS has been applied in several fields together with geography, forestry, urban development and designing, and environmental studies. Similarly, tourism has been a subject matter of interest to geographers, economists, business, environmental planners, anthropologists, and archeologists. This makes the potential applications of GIS in tourism vital. Moreover, maps are bestknown to play important roles in identifying and locating traveler attractions. GIS but provides the ability to extract completely different sets of knowledge (e.g. tourist attractions, hotels and their distances from each other, roads, settlements, vegetation, land use information, changes in tourism resources) from a map and use them as needed, as a result of the dynamic capability of GIS tools to include changes that occur over time to its database .

\section{RCENT USE OF GIS IN TOURISM SECTOR}

The use of GIS system is classified into 2 classes consistent with the consumer vis. Management user and public user. Public user is that the tourists using the maps for navigating towards their destination. They are fascinated by tourism geographic or location specific info about a place or a locality. Further, the traveler is also interested to understand regarding the accessible amenities, facilities and additionally the climate of the region or place wherever they will visit. The management users include individual employers like tour operators, tourism group, policy makers or an area municipal administration for tourism. Specific strategic designing or development. Management user is additional interested to understand the situation of their socio-economic background and potential location for new tourist sites within the region.

\section{RELATED WORK}

The use of GIS in tourism studies has being marginal although GIS technology has been in tourism related literature over the years. Dogru et.al (2004) designed a dynamic map browser interacting with the earthquake data for Turkey. The online mapping application provides information regarding earthquakes that provides facilities for perform spatial and attribute question by the users on the net [1]. Using Map Objects build the GIS application and MOIMS was used as a gateway program. The drawn maps are displayed on the web browser as a picture.

Seker et al (2002) applied GIS for supporting the design activities for touristry in Manavgat, situated in southern coast of Turkey, and targeted on the analysis, management, decision making using GIS techniques, and result was given on the net[2]. 
A Georeferenced information system (GeoRIST) has been applied in developing the touristry facility of agra, india for the travelling community at international and national level by Singh and Sharma et al. (2011) that integrates spatial information, statistical knowledge with textual data for developing a data model that may offer actual and full information for analysis and designing[3].

An intregrated tourism data system was applied by Zografos et al (2002) on travel and touristry that offer real time data whereas being on move with a value additional service (VAS) for the individual[4]. Tyagi (2014) developed a web based customized tourism data system (TIS) for eastern U.P., designed on GIS platform. the application offer an interactive dynamic mapping by showing the location of tourist destinations moreover as location of restaurants, travel firms, hospitals, security, passport office etc[5]. The Open source Map Guide was used for customizing and displaying the database on the internet once ready in Arc map. Hypertext markup language was used for designing the online page the eastern U.P. touristry web portal.

Hussain (2006) developed an interactive internet primarily based GIS application prototype for Hyderabad city to push the town's traveler activities and provide the users with an innovative idea to access the spatial contents of the city. The study was done to develop a GIS enabled on-line interactive guide for the tourists and in addition for the residents of Hyderabad through a prototype internet site, created using Arc IMS interface Developer and hypertext nomenclature was used for online page style[6].

Thecla. I et.al (2014) had designed and developed a GIS database for Anambra State of nigeria to induce economic benefits for tourism business[7]. GIS is provides information concerning the locations, facilities for tourist and resource that represents benefits to the tourism sector of any economy. The employment of GIS technology may assist the Anambra government additionally as the Nigerian government with higher designing of tourism infrastructure, location, production of upper quality maps showing tourist's sites. Jovanovic \&amp; Njegus (2008) has done a study related to the applying of GIS and it's components of in tourism and applied the GIS to style and develop the tourism destinations in Zlatibor (Cajetina) and Zlatar areas of serbia[8].Mohan Lalit et. al prepared an interactive tourist maps for Chandigarh city using the online GIS techniques and presenting the results on the web to produce the desired data on tourism/hospitality for the tourists[9]. The study developed a prototype application for promoting the touristry for town adding an appropriate query tools for the prototype system. A presentation was created by Aamir Ali on web and mobile GIS application development, together with the online GIS function, mobile GIS function, architecture, regarding the server side implementation for spatial database Postgis, oracle, web services WMS WFC WCS and server side implementation for mapping on GIS server like Geoserver, ARCIMS, Map server etc.

Marson et al. 2015 focuses on a GIS-based spatial decision support system (SDSS) application integrated with GIS functions and SDSS designs using user friendly graphic user interfaces (GUI) that may facilitate the tourists to decide on and set up their activities, according to their convenience for the Langkawi Island of malaysia. tourismdatabase, GIS Server, web client and Desktop GIS application together consist the tourism decision support system (TDSS) that are necessary for creating a GIS based decision support system[9].
Kommana (2013) used the open source software primarily Geoserver to design an online map application and creating it offered on the net that may be employed by any institute or organisation. the info revealed into Geoserver are often shared worldwide[10]. The user can overlay the Geoserver WMS layers, by choose background e.g. Google Earth, Open Street Map, etc. and adding the zoom in and out, pan, navigation, switch layer, layer summary using totally different symbols and designs. to make the dynamic website hypertext markup language, CSS and JQuery are used in this project.

Kumar et al (2015) developing an online GIS primarily based land information system for Bhopal city in open source environment. An online GIS prototype was created for geospatial data of Bhopal city that gives some practicality like pan, zoom, andbasic query analysis that additional with the web mapping application[11]. POSTGIS database and Open Layers libraries, Geoserver was used to set up and enhance the web site functions. Using three tier design the system was designed which contains3 layers client layer, Application Layer and database Layer. Web page design was finished hypertext markup language, ajax and Java Script and Open Layers.

Agrawal et al. (2014) focuses on develop web GIs framework on WAMP and apache tomcat on open source environment. they have been used WAMP server, ALOV, Quantum GIS and MySQL for first frame GIS work, on the other hand for second web GIS framework, Apache tomcat server, Geo Server, Quantum GIS, PostgreSQL and Post GIS are used[12].

\section{CASE STUDY 4.1 Nigeria - Anambra State}

Tourism has been noted to be one among the necessary sectors of the Nigerian economy[7]. Touristry could be a extremely advanced activity which needs tools that aid in an efficient decision-making to return to terms with the competitive economic, social and environmental demands of sustainable development. Geographic information system (GIS) is one amongst such tools. GIS being an information system that's capable of respondent questions on wherever facilities and resources are situated represents huge advantages to the touristry sector of any economy. The utilization of GIS technology might assist the Anambra state government additionally as the Nigerian government with higher designing of touristry infrastructure, location and dissemination of such infrastructure, production of higher quality maps showing tourists sites etc due to the dynamic capability of GIS tools to include changes that occur over time to its database.

Anambra State is one among the States within the eastern Region with various traveler attractions yawning for development. GIS could be a important tool which will be explored by the State to develop its touristry potentials and expand its touristry market. It offers correct location of distances between one attraction to the other, road networks, hotels, distance between hotels and attractions etc. If a traveler is armed with elaborated data about a destination it would increase his/her charm to such a destination. A GIS database for touristry in Anambra State was created using some designated roads, traveler attractions and facilities with the help of base maps and GPS

\subsection{Hydrabad}

Hyderabad is quite 400 years old and at the moment the fifth largest metropolitan town of India. It's additionally the capital city for the state of Andhra Pradesh[6]. Secunderabad is a 
twin city connected to Hyderabad. The city is finite by the coordinates, latitudes - $17^{\circ}-30^{`}-00^{\prime \prime} \mathrm{N}$ \&amp; $17^{\circ}-19^{`}-48^{\prime \prime} \mathrm{N}$ and longitudes $-78^{\circ}-22^{\prime}-12^{\prime \prime} \mathrm{E}$ \&amp; $78^{\circ}-34^{\prime}-48^{\prime \prime} \mathrm{E}$ and spread on a region of 260 sq. kms. with a population of 5.5 million. It's famous for its wealthy history and culture with natural and discipline beauty, mosques, minarets, temples, chapels, bazaars and parks. It's additionally several modern shopping malls that raise the charm of town. Presently the city is hosting several international and IT corporations from around the world with a well developed infrastructure to support connected activities and because of this it's additionally referred to as as "Cyberabad" which implies Cyber town. the city has become a hub for many of the software development firms establishing their research activities. It's got several tourer attractions and trendy facilities for the guests that makes it a major tourer destination. With all the means that and efforts to serve the world, currently town has to be presented in a higher way to the may be done by using the Web-based interactive mapping using the GIS technology.

\subsection{Zlatibor and Zlatar}

GIS use has up to now provided booming results that promote importance of information over technology[8]. The fact is that geographic information in actual world come in many alternative formats. During this study GIS has been established as a tool for grouping, analyzing, modelling and visual presentation of tourist information. Also, GIS is employed for bringing the georeferenced information (spatial and non spatial) of geographic location Zlatibor and Zlatar into digital maps. Every object is appointed to a thematic layer. Every layer combines connected objects like roads, building, or watercourses. To integrate touristry data the standard layer model with layers like roads, buildings, vegetation, watercourses, etc., should be enlarged with further touristry layers like hotels, restaurants, sights and additional infrastructure layers.

Geographical information system could be a quickly increasing field sanctioning the development of applications that manage and use geographic information together with different media. Within the touristry business, government strategy, decision making, GIS is employed to provide: digital basic map, digital files for analyzing and mapping, digital files for mobile mapping and modelling, digital multimedia system.

\section{STUDY AREA-AURANGABAD (MAHARASHTRA)}

Aurangabad city is a historic city in situated within the heart of Maharashtra. A tourist hub enclosed with several notable historical and culture monuments and natural resorts together with the Ajanta and also the Ellora Caves, Bibi Ka maqbara and Panchakki and development of the tourism information with its trendy tourist facilities, destinations, and activities. it is speedily turning into a hot spot for tourist from around the world due to its exotic locations and facilities offer by the govt.. the city is located between $19^{\circ} 53^{\prime} 0 " \mathrm{~N}$ Latitude and $75^{\circ} 20^{\prime} 00^{\prime \prime} \mathrm{E}$ line of longitude and also the total geographic area of the is 135.75 sq.k.m . The city of 54 Gates however only 13 have survived over period of your time and therefore the presence of those can be felt as going on one drive within the city. In presently there are 35 tourist attractions/ locations in city and these days city has annual flow of 25 lakh tourists per annum and that continues to be increasing. The tourism potential of the district isn't absolutely tapped because of international gaps, connectivity, Services Quality, inadequate basics amenities and promoting promotion. However there are numerous issues faced by the Aurangabad tourism for the development of tourism a number of them are lack of correct infrastructure, Access and property, Amenities, Service level. The appliance providing information of places and sanctioning the availability of recent good services. Geographical information permits users to look at places as if standing upon them. Tour with Themed information, that highlights tourist attractions, provides its users a virtual tour of Aurangabad city. The help of the GIS application the tourist are going to be ready to understand the information regarding the place close to city and explore regarding the tourist place all necessary information. due to the development of the GIS based tourist information the guests will be mange and arrange their visits and complete their journey with additional comfort and ease from the beginning to end which may be determined simply and consistently using by the study area and exposed with the GIS but additionally well-tried that may be applied to those studies. The GIS can be acts as potential techniques in designing, managing and promoting the tourism product. Presently the tourism is being promoted and marketed to the world through the internet and web as one of the mediums of advertising. However still it's must be projected in a very higher way to the client with the utmost potential information to increase its marketability.

\section{METHODOLOGY}

As shows in the Fig 2 after collecting the primary and secondary data of Aurangabad city from various sources, this data will be prepared on ArcGIS environment. The road network is digitized from google earth and other points file like tourist places, hotels, restaurants, stations etc. are also collect from existing google earth point location for the study area were digitized from the satellite image. The locations of tourist spots are collected by using GPS. The GPS points are imported into google earth. After saving the all data layers as $\mathrm{kml}$ file all $\mathrm{kml}$ file are exported to shape file using the global mapper. The shape files are add to the arc map and creating the thematic layers as well as add the attributes for the individual's layers. The all shape file that contains the attributes are load into GIS database using shape file environment.

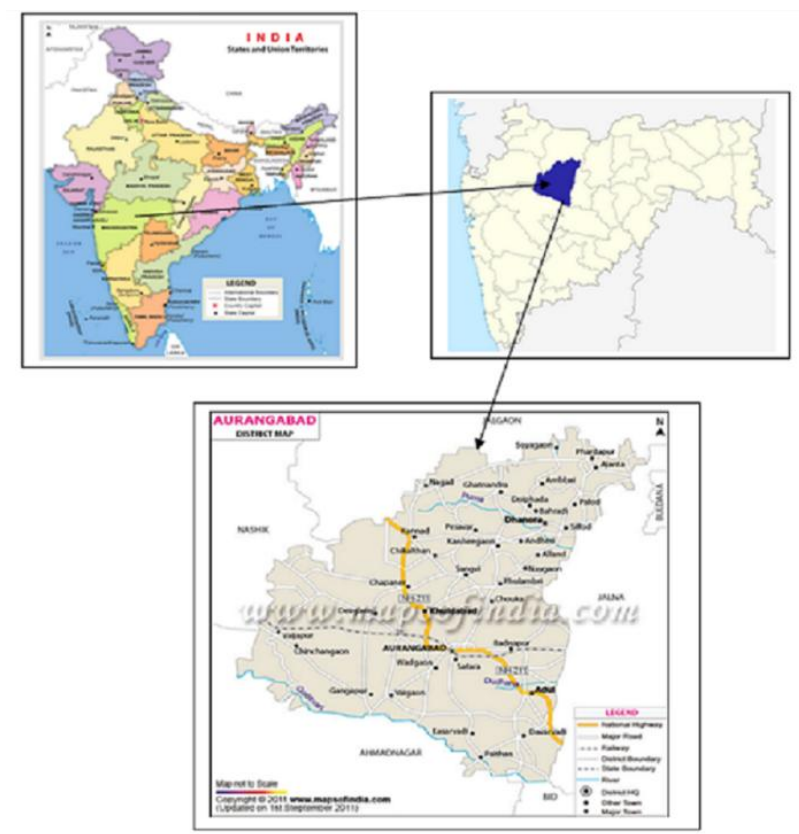

Fig 1: Study area-Aurangabad Region, Maharashtra State, India 


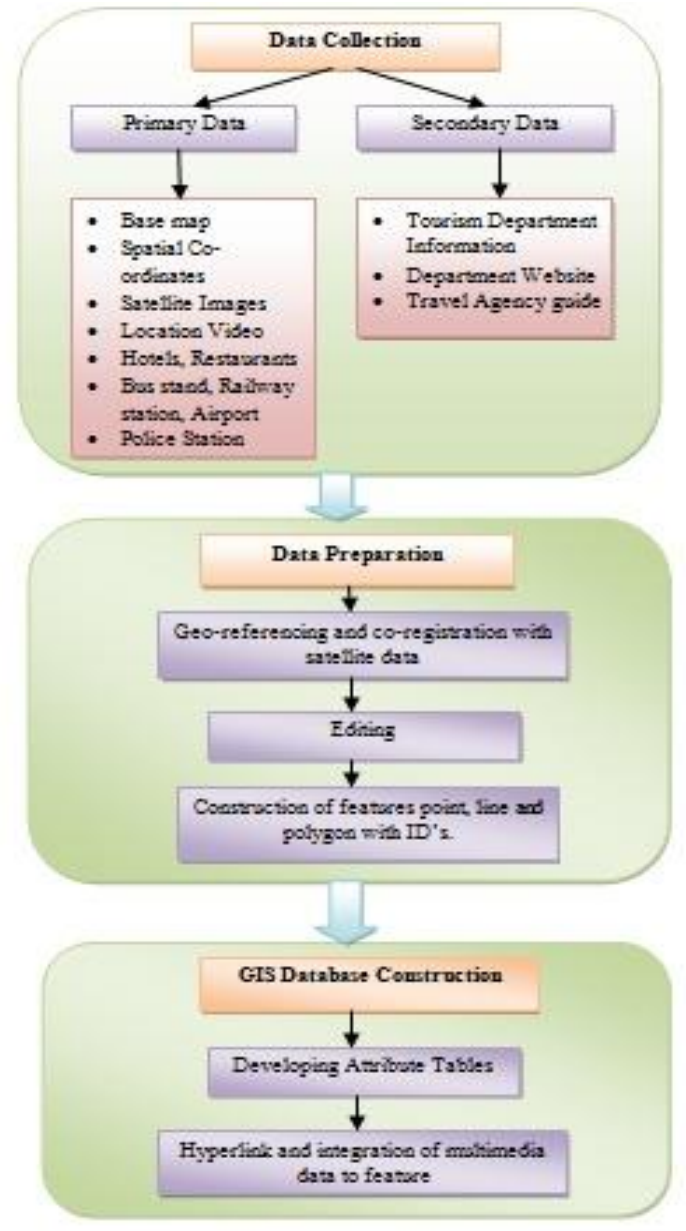

Fig 2: Schematic representation of Methodology followed in study

\section{CONCLUSION AND FUTURE SCOPE}

Tourism has been pointed as one of the world's largest, quick and speedy growing sector with a contribution of 100 percent to global gdp, making employment for maximum people. the requirement of GIS to tourism cannot be overemphasized. It is helpful to each tourist operators and tourists themselves. Its ability to feature changes in an existing destination makes it appealing to marketers whereas changes brought by tourist activities/tourism related activities is monitored with GIS thereby making certain property because such changes will be monitored and remedied if it's harmful. GIS being an information system that is capable of answering questions on wherever facilities and resources are located presents huge advantages. Aurangabad is one in all the district within the maharashtra state with various tourist attractions yawning for development. GIS is a necessary tool that may be explored by the State to develop its business enterprise potentials and expand its business enterprise market. it'll offer correct location of distances between one attraction to the other, road networks, hotels, distance between hotels and attractions etc. If a tourist is armed with elaborated data about a destination it would increase his/her attractiveness to such a destination. Therefore, the application of GIS in tourism is usually recommended as a result of the easiness and fastness in characteristic tourist sites and attractions with attended details so that Aurangabad can have a comprehensive map of what they have in every location.

\section{ACKNOWLEDGEMENT}

I am thankful to Dr. S. C. Mehrotra, Geospatial Chair Professor for suggestions. I am also thankful to Department of Computer Science and Information Technology, BAMU, Aurangabad for providing facilities in the department.

\section{REFERENCES}

[1] Dogru, A. G., Selcuk, T., Ozener, H., Gurkan, O. \& Toz, G. Developing a web-based gis application for earthquake information. At http: // cartesianos. Com / geodoc / isprs2004/yf/papers/954.pdf

[2] Duran, E., Seker, D. Z. \& Shrestha, M. Web based information system for tourism resort: A case study for side/Manavgat. roceedings for XXth International Society for Photogrammetry and Remote Sensing, Istanbul, Turkey: 2 July 12-23 (2004).

[3] Singh, S.P., Sharma, J., Singh, P., "A GeoReferenced Information System for Tourism (GeoRIST)". International journal ofgeomatics and geosciences, Volume 2, No 2, (2011)

[4] Zografos, K. G. and Madas, M. A. "A Travel \& tourism information system providing real-time, value-added logisticalservices on the move," in Proc. First International Conference on Mobile Business, 2002.

[5] Tyagi., N., "Web GIS application for customized tourist information system for Eastern U. P., India". Journal ofGeomatics, Vol 8 No. 1 April (2014).

[6] Hashmi, M. M. H. Explore Hyderabad: An Interactive Web-based GIS Application Prototype. (2006). At http://www.divaortal.org/smash/record.jsf?pid=diva2:21 905

[7] Akukwe, Thecla I. 1 and Odum, Chigozie, J. "Designing and Developing a Gis Database For Tourism In Nigeria: The CaseOf Anambra State". IOSR Journal Of Humanities And Social Science (IOSR-JHSS) Volume 19, Issue 10, Ver. VIII (Oct. 2014),109-120

[8] Jovanović, V. \& Njeguš, A. "The application of GIS and its components in tourism." Yugoslav Journal of OperationsResearch ISSN: 0354-0243 EISSN: 23346043 vol. 18 , no. 2 (2008).

[9] Masron, T., Mohamed, B. \& Marzuki, A. Gis base tourism decision support system for Langkawi island, Kedah, Malaysia.Theoretical \& Empirical Researches in Urban Management, vol.10, Issue 2 (2015).

[10] Kommana, K. Implementation of a Geoserver Application for GIS Data Distribution and Manipulation. (2013). At http://www.diva-portal. org/ smash/ record.jsf? pid=diva2:640096

[11] Kumar, A. \& Diwakar, P. S. "Web GIS based Land information System for Bhopal City using open Source Software and Libraries." At http:// ijsetr.org/ wpcontent/uploads/2015/01/IJSETR-VOL-4-ISSUE-1154-160.pdf

[12] Agrawal, S. \& Gupta, R. D. Development and Comparison of Open Source based Web GIS Frameworks on WAMP and Apache Tomcat Web Servers. ISPRS - International Archives of the Photogrammetry, Remote Sensing and Spatial Information Sciences XL-4, 1-5 (2014). 